\title{
Himalayan Wolf Attack of a Twelve-Year-Old Case at High Altitude
}

\author{
Inam Danish Khan ${ }^{1, *}$ \\ ${ }^{1}$ Assistant Professor (Clinical Microbiology and Infectious Diseases), Army College of Medical Sciences and Base Hospital, Delhi Cantt 110010, India \\ "Corresponding author: Inam Danish Khan, Assistant Professor (Clinical Microbiology and Infectious Diseases), Army College of Medical Sciences and Base Hospital, Delhi \\ Cantt 110010, India. Tel: +91-9836569777, Fax: +91-1125693490, E-mail: titan_afmc@yahoo.com
}

Received 2016 December 05; Revised 2017 January 07; Accepted 2017 January 08.

\begin{abstract}
Introduction: Animal attack is a major public health problem worldwide with mortality reported to the centre for disease control and prevention. In the United States, a person is more likely to be killed by an animal than from lightning strike. Wolves are apex predators and have attacked humans since antiquity. Wolf attacks remain a reality in the US, Canada, Russia, and India, despite advances in security and surveillance technologies.

Case Presentation: A 12-year-old male sustained multiple lacerations on his face and hands leading to extensive bleeding after a predatory wolf attack at high altitude. Tachycardia with feeble pulse, tachypnea, and mild hypothermia were present. The child was managed through resuscitation, rewarming, tetanus, rabies, and antimicrobial prophylaxis, and transferred to tertiary care. Wounds were not sutured.

Conclusions: Wolf-human interactions require diligent efforts for threat assessment, mitigation measures, and community responses under one health approach. Communities in close proximity of wolf populations need to be supported with real time wildlife surveillance and containment systems.
\end{abstract}

Keywords: Wolf Attack, High Altitude, Canis Lupus Chanco, Hypothermia, One Health, Anti-Rabies Prophylaxis, Wildlife Ethology

\section{Introduction}

While forest ecosystems form the subsistence economy of human communities in the conservation landscape, wild animals have been a menace to peaceful existence since the history of civilization. Animal attack is a major public health problem worldwide, with mortality reportable to the centre for disease control and prevention. Seventeen species of large mammalian carnivores have been documented to kill humans, although, only six are encountered regularly. In the United States, a person is more likely to be killed by an animal than from lightning strike. Wolves are apex predators and have attacked humans since antiquity. Wolves have been claiming lives pan-India for the past two centuries (1). With the current economic and human development of 21st century, wolf attacks remain a reality in US, Canada, Russia, and India (2). A wolf attack on a 12-year-old male under discussion brings forth the perspectives on human settlements in wolf habitats.

\section{Case Presentation}

A 12-year-old male was brought to a low resource healthcare center located in the Indian Himalayas at 9000 feet at $\mathbf{2 2 0 0}$ hours, during winter with an alleged history of wolf attack around 2000 hours. On first examination, his head and face was covered with clotted and dried blood with some fresh blood oozing from multiple sources. The child was conscious, oriented, and responding to commands. Tachycardia with feeble pulse, tachypnea, and mild hypothermia were present. Detailed local examination revealed multiple lacerations with oozing of blood on forehead, eyes, cheeks, nose, ears, upper lip, scalp, and both hands. There was ongoing anterior and posterior nasal bleeding. Lacerations over the forehead, cheeks, and lips were 1 to $5 \mathrm{~cm}$ in length and 4 to $10 \mathrm{~mm}$ deep. Both superior and inferior palpebrae of right eye were torn apart and lay hanging laterally. Left palpebrae were intact. There was no apparent injury to either globe of eyes. A large laceration over the bridge of nose extending below the left eye leading to exposure of nasal and facial bones was seen. Both ears were mauled by the wolf, leading to soft tissue injury around the ears. There were no serious injuries on the neck and other parts of the body (Figure 1).

The child was looked after in a heated room with passive heating with electric blanket and warm ringer lactate infusion. Lacerated wounds were irrigated by warm sterile normal saline followed by local injection of empirical antimicrobials. Tetanus prophylaxis and intravenous antimicrobials were administered. Anti-rabies prophylaxis included subcutaneous and intramuscular administration of tissue culture based rabies vaccine in divided doses. Nasal packing was followed by loose bandaging of eyes and facial wounds. Wounds were not sutured (3). The case was

Copyright ( $)$ 2017, AJA University of Medical Sciences. This is an open-access article distributed under the terms of the Creative Commons Attribution-NonCommercial 4.0 International License (http://creativecommons.org/licenses/by-nc/4.0/) which permits copy and redistribute the material just in noncommercial usages, provided the original work is properly cited. 

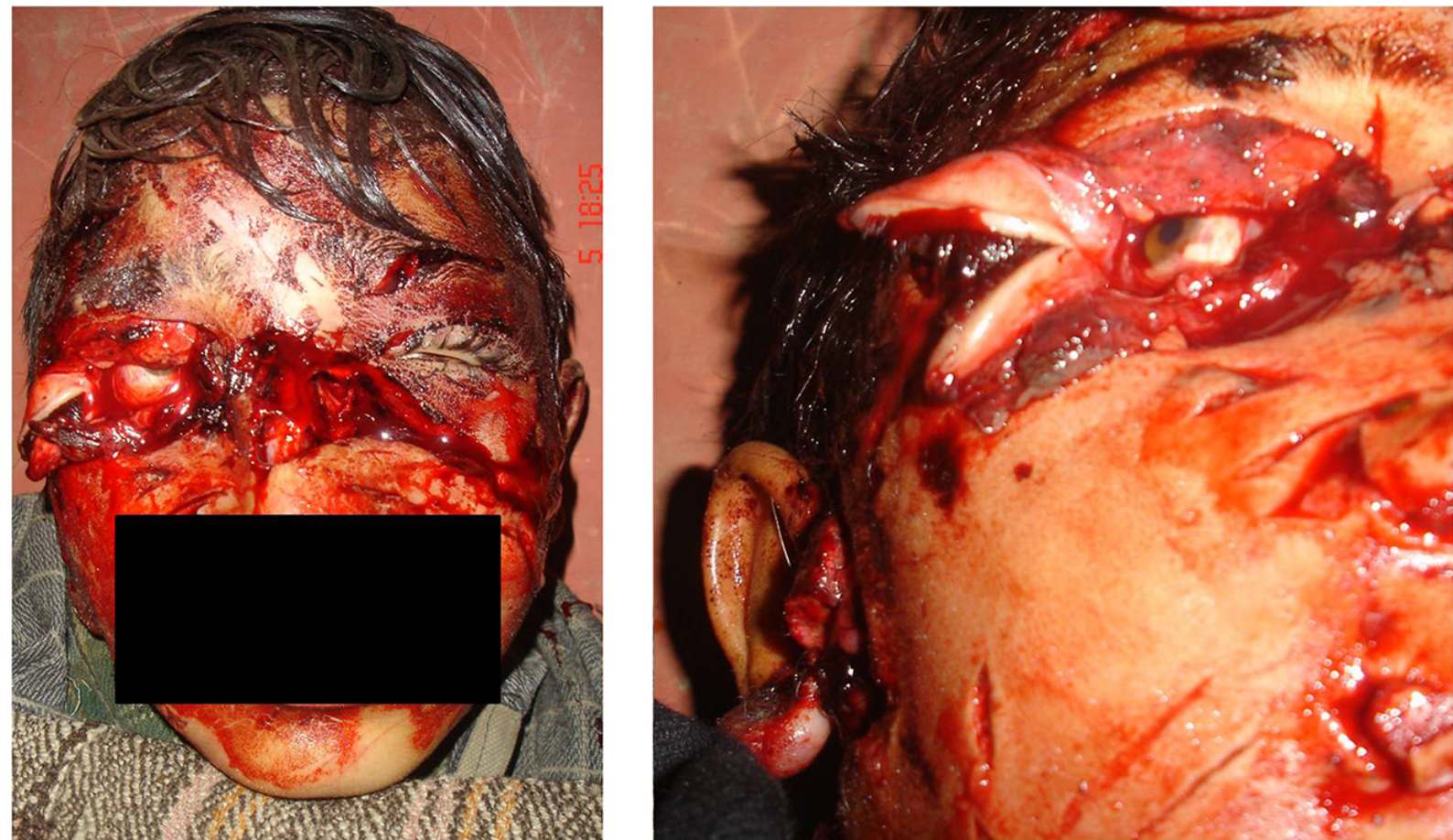

Figure 1. Wolf Attack of a 12-Year-Old Male Showing Extensive Lacerations of Face with Disruption of Right Eyelids and Exposure of Nasal Bone

transferred to a tertiary care facility with planned staging at a secondary care facility at 0100 hours. Follow up after a month revealed survival of the case with healing of wounds while being considered for reconstructive intervention at a tertiary care facility.

\section{Discussion}

Wolf, Canis lupus, is the largest member of Canidae family. It is native to wilderness and remote areas in tropical, subtropical, temperate, desert, cold continental, and polar climate of Eurasia and North America. Larger wolves are seen in Alaska, Canada, and Russia compared to their smaller cousins in Middle-East and South Asia, increasing proportionally in size with latitude. Wolves have a long history of association with communities in primary occupations such as nomadism, farming, mining, and military. They have been mentioned in the literature and folklore more than other wildlife species. The Himalayan wolf (Canis lupus chanco or Canis himalayensis), found in India, Nepal, and Tibet, is a critically endangered species (4).

Historical records have reported that 7600 civilians and soldiers were killed by wolves during 1362 - 1918, of which 4600 were killed by non-rabid wolves. Wolf packs can target adults and individual wolves may prey on children by silently entering the house, silencing children by biting the mouth and nose and carrying the child away. Wolves have been notorious for preying on children in India and Iran $(1,2)$. Wolf attacks on humans are on an increase in the US, Canada, and Russia. A super pack of 400 wolves killing humans and animals since 2011 in Siberia, had to be tackled with special task-forces and hunt prizes (5). Wolf attacks are categorized in rabid and nonrabid. Non-rabid attacks comprise of provoked (defensive/disciplinary) or unprovoked. Unprovoked attacks can be predatory, investigative or agonistic. Wolf transmitted rabies is common in the Mediterranean, Eastern Europe, Middle-East, and Central-Asia (4). Bites from rabid wolves are considered 15 times more dangerous than rabid dogs $(4,6)$. Deaths occur due to bleeding, tissue devitalization, and infections, including rabies, renal failure, and sepsis. The world health organization uses identical coding for animal attacks, however animal attacks go under-reported in developing tropical countries, which may have a higher incidence of animal attacks (3).

The child was badly mauled by the wolf leading to soft tissue injuries on the face, extensive bleeding, disruption of eyelids, and facial disfigurement. Injuries to the face comprise $10 \%$ of the total animal attack injuries. Unattended children are likely to enter wilderness and mistake wolves for dogs. Children are commonly bitten by ani- 
mals on the face, with two-thirds of bites found in children aged 10 or younger. Bites typically occur in late afternoon and evening, as seen in this case. While the child was exposed to low temperatures of $-100^{\circ} \mathrm{C}$ at 9200 feet, the ensuing hypothermia may have been protective against extensive bleeding, promoting survival of the case. The case was managed and evacuated within the limitations of the remote low resource set up. There was unavailability of whole blood or component transfusion, anti-rabies immunoglobulin, and immediate air evacuation. The attack investigated here is likely to be a predatory attack, as rabid and defensive attacks are limited to quick bites, whereas the injuries to the child represent prolonged struggle with the wolf while trying to protect his face/throat with his hands (1). The frequency of lupine attacks depends on geography, terrain, proximity to the wildlife, wildfires, and lack of food, which is common in harsh winters $(4,6)$. There is no data on wolf-rabies in from the region, nevertheless the possibility of wolf-rabies cannot be ruled out.

The emergence of exotic infectious diseases attributable to increasing contact between human and animals, from novel animal reservoirs and vector-borne transmission has lead to concept development on "EcoHealth", "GeoHealth", and "One Health", which integrate co-existence and sustainability of humans, animals, and environmental constructs. Overall, 61\% of 1415 known pathogens are known to be transmitted between humans and animals $(7,8)$. One Health re-emphasizes on global health determinants of international human travel and wildlife trade, social health determinants of pets and livestock associated diseases, environmental health determinants of global warming, deforestation and rapid urbanization, evolutionary health determinants of emerging and re-emerging zoonotic diseases, and antimicrobial resistance, which has universal genomic connotations, and epidemiological correlates $(9,10)$. While one health has furthered new paradigms of comparative, conservation, evolutionary, translational, and molecular medicine, there exists a felt need towards political commitment, intersectoral coordination, capacity building, and fostering expertise to inculcate transdisciplinarity $(11,12)$.

\subsection{Conclusion}

Wolf-human interactions require diligent efforts at threat assessment, mitigation measures, and community responses under one health approach. Communities in close proximity to wolf populations need to be supported with real time wildlife surveillance and containment systems through fencing, thermal imaging, infectious diseases, and vector surveillance to characterize the spatiotemporal patterns of wildlife ethology and ecosystems.

\section{Acknowledgments}

The author would like to acknowledge the medical doctors in secondary and tertiary care for their efforts towards the patient.

\section{Footnotes}

Authors' Contribution: The author served as the medical officer at $2700 \mathrm{~m} / 9000 \mathrm{ft}$ and attended the patient in low resource healthcare set up located on the Indian $\mathrm{Hi}$ malayas.

Conflicts Of Interest/Disclosures: No conflicts of interest.

Ethical Approval: The patient's consent and ethical approval were obtained by the institutional committee.

\section{Funding/Support: None.}

\section{References}

1. Jhala YV, Sharma DK. Child-lifting by wolves in eastern Uttar Pradesh, India.J Wild Res (Boguslaw Bobek). 1997;2:94-101.

2. Rathod NJ, Salunke S, Bawiskar VR. Clinical profile of wolf bite cases in Jalgaon district. J Assoc Physicians India. 1997;45(11):866-7. [PubMed: 11229189].

3. WHO . Rabies: Local treatment of wounds [cited 25 Oct]. Available from: http://www.who.int/rabies/human/localwounds/en/.

4. Linnell JD, Andersen R, Andersone Z, Balciauskas L, Blanco JC, Boitani L, et al. The fear of wolves: a review of wolf attacks on people. NINA Oppdragsmelding. 2002;731:65.

5. Oliphant R. Wolf attacks lead to state of emergency in Russia's Siberia region. The Telegraph (Science). 2013.

6. Turkmen S, Sahin A, Gunaydin M, Tatli O, Karaca Y, Turedi S, et al. A wild wolf attack and its unfortunate outcome: rabies and death. Wilderness Environ Med. 2012;23(3):248-50. doi: 10.1016/j.wem.2012.03.009. [PubMed: 22796088].

7. Khan ID, Sahni AK, Bharadwaj R, Lall M, Jindal AK, Sashindran VK. Emerging organisms in a tertiary healthcare set up. Med JArmed Forces India. 2014;70(2):120-8. doi: 10.1016/j.mjafi.2013.09.005. [PubMed: 24843199].

8. Khan ID, Lall M, Sen S, Ninawe SM, Chandola P. Multiresistant Elizabethkingia meningoseptica infections in tertiary care. Med J Armed Forces India. 2015;71(3):282-6. doi: 10.1016/j.mjafi.2014.02.002. [PubMed: 26288498].

9. Jindal AK, Pandya K, Khan ID. Antimicrobial resistance: A public health challenge. Med J Armed Forces India. 2015;71(2):178-81. doi: 10.1016/j.mjafi.2014.04.011. [PubMed: 25859082].

10. Khan ID, Sahni AK. Bacterial infections and emerging resistance in renal transplant recipients. Bangladesh Journal of Medical Science. 2015;14(1):14-21.

11. Danish Khan I. Grenade explosion leading to penetrative brain trauma and demise of three children during high altitude counter insurgency operations. J ARCH MIL MED. 2016;4(4) doi: $10.5812 /$ jamm.44324.

12. The FAO-OIE-WHO Collaboration . A Tripartite Concept Note 2010. Available from: http://web.oie.int/downld/FINAL_CONCEPT_ NOTE_Hanoi.pdf. 